\title{
Delineating the serotype-specific neutralizing antibody response to a live attenuated tetravalent dengue vaccine
}

\author{
Gregory D. Gromowski ${ }^{a}{ }^{*}$, Sandra Henein ${ }^{b}$, Chandrika B. Kannadka ${ }^{a}$, David A. Barvir ${ }^{a}$, \\ Stephen J. Thomas a ${ }^{\text {, Aravinda M. de Silva }}{ }^{\text {b }}$, Richard G. Jarman ${ }^{\text {a }}$ \\ a Viral Diseases Branch, Walter Reed Army Institute of Research, Silver Spring, MD, USA \\ ${ }^{\mathrm{b}}$ Department of Microbiology and Immunology, University of North Carolina, Chapel Hill, NC, USA
}

\section{A R T I C L E I N F O}

Article history:

Received 19 September 2017

Received in revised form 2 February 2018

Accepted 21 March 2018

Available online 27 March 2018

\section{Keywords:}

Dengue

Live attenuated vaccine

Neutralizing antibody

\begin{abstract}
A B S T R A C T
The dengue virus (DENV) vaccines that are licensed or in clinical development consist of DENV serotype 1-4 tetravalent formulations given simultaneously and are not acquired sequentially like natural infections. It is unclear what effect this has on development of protective levels of immunity to all four serotypes. Serotype-specific neutralizing antibody (NAb) is considered the most relevant correlate of protection from dengue disease. Here we assessed levels of serotype-specific and cross-reactive NAb in immune sera from 10 subjects vaccinated with a live attenuated tetravalent DENV vaccine developed at the Walter Reed Army Institute of Research. The majority of subjects NAb responses to DENV-2 and DENV-4 were type-specific, while their NAb responses to DENV-1 and DENV-3 were primarily crossreactive. Vaccine virus RNAemia has been most frequently detected for DENV-2 and DENV-4 in vaccinated subjects, strongly suggesting that replication is important for eliciting serotype-specific immunity.
\end{abstract}

\section{Introduction}

Dengue virus (DENV) serotypes 1-4 are of significant importance to public health in endemic countries, which are widely distributed in tropical and subtropical areas of the world. It has been estimated that 390 million DENV infections occur annually [1]. Dengue vaccine development has been complicated by cocirculation of all four DENV serotypes in endemic countries and the possibility of sequential infections with different serotypes causing more severe disease, which necessitates a tetravalent vaccine for simultaneous protection against all 4 serotypes. Historical evidence suggests that infection with any one DENV serotype will provide life-long immunity to that serotype and short-term crossprotection against the heterologous DENV serotypes that lasts only a few months [2]. This paradigm has been challenged by more recent studies indicating that homologous re-infections, although rare, can occur in some people [3]. The immune responses to post-primary DENV infections display an anamnestic response that is broadly cross-reactive among DENV serotypes and longer periods of cross-protection are observed [4-7].

The DENV vaccines that are currently licensed or in clinical development are tetravalent formulations given simultaneously

\footnotetext{
* Corresponding author.

E-mail address: gregory.d.gromowski.civ@mail.mil (G.D. Gromowski).
}

and DENV 1-4 are not acquired sequentially like they are in endemic areas. It is unclear what effect this has on development of protective levels of immunity in humans. Furthermore, neutralizing antibody (NAb) measured by the plaque reduction neutralization test (PRNT) is considered the most relevant correlate of protection and is routinely used to evaluate vaccine efficacy. However, only moderate clinical efficacy in phase III trials was observed for recipients of the CYD-TDV vaccine (Sanofi Pasteur) who had balanced tetravalent NAb responses [8-10]. This indicates that our understanding of NAbs as a correlate of protection needs to be refined.

The DENV envelope protein is the major target of neutralizing antibodies [11]. Potently neutralizing human NAbs have been mapped to epitopes on the E protein that link multiple E protein monomers [12-18]. The presence of serotype-specific NAb is evidence of previous exposure to a specific DENV serotype and if it were elicited by natural or experimental infection then it would be expected to correlate with protection against homologous reinfection, as previous human studies have demonstrated $[2,19]$. Cross-reactive NAb is not necessarily an indicator of prior exposure to any specific serotypes but has been shown to reduce the risk of disease from heterologous DENV infection [20]. Recently, virusspecific serum antibody depletion methods have been developed to determine the contribution made by DENV type-specific and cross-reactive antibodies to virus neutralization in vitro after primary and secondary infections or immunizations [7,12,19,21]. 
After a primary DENV infection, serotype-specific antibodies contribute most to neutralizing activity against the infecting serotype, while cross-reactive antibodies contribute less to neutralization and can mediate enhancement of heterologous DENV infection in cell culture and in mice [22]. The proportion of cross-reactive antibodies that contribute to virus neutralization appeared to increase after secondary DENV infection or immunization [7,21]. After immunization with the CYD-TDV vaccine, a combination of all four serotypes delivered simultaneously, subjects had type-specific NAb primarily to DENV-4 and cross-reactive NAb to DENV 1-3 [19]. This bias was hypothesized to be the result of better replication of the DENV-4 vaccine component in most subjects.

The live attenuated CYD-TDV vaccine has been licensed for use in several endemic countries (trademarked as Dengvaxia) including Brazil, El Salvador, Mexico, Paraguay, and the Philippines [23-26]. However, the CYD-TDV vaccine had only moderate efficacy in DENV seronegative individuals, limiting its utility in these populations. Two other live attenuated vaccines are in clinical development. The live attenuated TV003/TV005 vaccine (US National Institutes of Health $[\mathrm{NIH}]$ ) is in phase III development and has been licensed to Merck, and companies in Brazil (Instituto Butantan), India (Panacea Biotec and Serum Institute of India), and Vietnam (Vabiotech) [27-31]. The TDV vaccine (Takeda) is currently undergoing phase III studies [32-35].

A live attenuated tetravalent dengue vaccine was developed at Walter Reed Army Institute of Research (WRAIR) in collaboration with GlaxoSmithKline (GSK) [36-38]. The DENV 1-4 live attenuated vaccine (TDENV) viruses developed at WRAIR were attenuated by serial passage in primary dog kidney (PDK) cells [38-50]. A safe and immunogenic formulation of TDENV was selected based on a phase II clinical study in flavivirus naïve subjects [46]. This formulation demonstrated good safety and efficacy in infants and children $[47,48]$. The TDENV vaccine viruses were re-derived and tested in a phase II study in flavivirus naïve adults, demonstrating adequate safety and immunogenicity after two doses [49]. The TDENV vaccine, in combination with a tetravalent DENV purified inactivated vaccine [51] is currently undergoing clinical evaluation using a heterologous prime-boost approach. In the current study, sera from 10 flavivirus naive subjects that received two doses of TDENV were evaluated for levels of serotype-specific and crossreactive $\mathrm{NAb}$.

\section{Material and methods}

\subsection{Viruses and cells}

The DENV strains used for in vitro assays are DENV-1 West Pac 74, DENV-2 S16803, DENV-3 CH53489, and DENV-4 TVP-360. Virus stocks were produced by passage in Aedes albopictus mosquito C6/36 cells as described previously [52].

\subsection{Vaccine study sera}

The vaccine study design is described in detail in Ref. [49] and was approved by the US Army Human Subjects Research Review Board and the Office of the Surgeon General (www.clinicaltrials.gov identifier: NCT00350337). A total of 10 sera from study day 210 (30 days post dose two) were selected from subjects that were flavivirus naïve, had received two doses of vaccine, and had consented to use of their sera.

\subsection{Purification of dengue viruses}

The DENV 1-4 were amplified in Vero cells, concentrated by tangential flow ultrafiltration, and purified by sucrose gradient ultracentrifugation as described previously [53].

\subsection{Depletion of DENV-specific antibodies from human sera}

The antibody depletion method was carried out as described previously [12]. Purified DENV or BSA control protein was adsorbed onto $4 \mu \mathrm{m}$ Polybead polystyrene microspheres following the manufacturer's instructions (Polysciences, Inc.). The polystyrene microspheres were washed three times with $0.1 \mathrm{M}$ borate buffer ( $\mathrm{pH}$ 8.5) and were incubated with purified DENV or BSA control protein in borate buffer overnight at room temperature. The control and DENV-adsorbed beads are blocked three times with BSA $(10 \mathrm{mg} / \mathrm{ml})$ in borate buffer for $30 \mathrm{~min}$ at room temperature and washed six times with PBS. Human immune sera were depleted of DENV-specific antibody by incubation with virus-adsorbed beads for $2 \mathrm{~h}$ at $37^{\circ} \mathrm{C}$ with gentle mixing. Sequential rounds of antibody depletion were performed and the depleted sera were tested for successful removal of the desired DENV-specific antibodies by ELISA.

\subsection{ELISA}

Binding of human immune sera to purified DENV 1-4 was measured as described previously [12]. ELISA plates were coated with $50 \mathrm{ng}$ of purified virus. Bound antibody was detected with an alkaline phosphatase conjugated goat anti-human IgG antibody and p-nitrophenyl phosphate substrate and was read at an absorbance of $405 \mathrm{~nm}$ on a spectrophotometer. End-point titration of serum samples was initially performed to assess the relative levels of DENV-reactive antibody. To confirm successful removal of antibody by the depletion method the virus antigen-depleted or control-depleted sera were tested for binding at a 1:100 dilution. The DENV antigens used for depletion of a given serum sample matched those used for testing that depleted sample by ELISA.

\subsection{Flow cytometry-based 50\% neutralization (FlowNT50) assay}

Neutralizing antibody titers in heat-inactivated sera were determined using a flow cytometry-based neutralization assay in U937 cells expressing DC-SIGN as previously described [12,54]. Data were analyzed by nonlinear regression to determine $50 \%$ neutralization titers in GraphPad Prism 6. Some sera had low NAb titers near the 1:40 limit of quantification of the assay and made it more difficult to fully resolve the type-specific and crossreactive NAb populations. Also, in some cases, the control depleted sera had marked reductions in NAb titer compared to undepleted sera, which is likely due to non-specific removal of DENV antibody and neutralization assay variability.

\subsection{Viremia determination by $R T-q P C R$ (RNAemia)}

A DENV serotype-specific RT-qPCR assay (described in Ref. [49]) to assess vaccine virus RNAemia in all study subjects on two separate study visits in a 14 day window after both doses of vaccine. Depending on the subject, the first sampling time-point was day $2,5,8$ or 12 and the second sampling time-point was day 8,12 , or 14 . The limit of detection of the assay was 6500 genome equivalents (GEQ)/ml for DENV-1, 160,000 GEQ/ml for DENV-2, 1250 $\mathrm{GEQ} / \mathrm{ml}$ for DENV-3, and 33,000 GEQ/ml for DENV-4.

\subsection{Statistical analysis}

All statistical analyses were performed with GraphPad Prism version 6.02. The levels of seroconversion to DENV 1-4 were compared among and within groups by Fisher's exact test with $\mathrm{p}<0.05$ required for significance. The NAb responses to DENV 1-4 were compared among and within groups using $\log 10$ transformed titers 
in an ANOVA with Tukey's multiple comparisons test and $\mathrm{p}<0.05$ required for significance.

\section{Results}

\subsection{Selection of sera for antibody depletions}

Ten sera from subjects that received two doses of live attenuated tetravalent DENV vaccine in any of three vaccination groups (PRE-F17, TDEN F17, and TDEN F19) [49] were selected for DENV-specific antibody depletion to estimate levels of typespecific and cross-reactive NAb. The PRE-F17 vaccine formulation was optimized in a previous phase I clinical study [38]. The F17 vaccine formulation matched that of PRE-F17 but contained vaccine viruses that were re-derived by transfection of purified viral RNA into fetal rhesus lung cells. The F19 vaccine formulation matched F17 except for a moderate 4-fold lower dose of the DENV-4 component. Sera from all subjects that had consented to use from the original study were ranked based on DENV 1-4 $\mathrm{NAb}$ valency and then by magnitude of NAb titers. The data in Table 1 indicate that the selected sera are representative of the overall NAb response to all three vaccine formulations with similar seroconversion and geometric mean neutralizing antibody titers (GMTs), except for DENV-2 that had a significantly higher GMT compared to groups TDEN F17 and F19. A microneutralization (MN50) assay was used to determine 50\% titers previously [49]. Here we used a flow cytometry-based neutralization assay that gives comparable 50\% neutralization titers. The FlowNT50 titers against DENV 1-4 are shown in Table 2. There were 5 tetravalent
(50\%), 1 trivalent (10\%), 3 bivalent (30\%), and 1 monovalent $(10 \%)$ $\mathrm{NAb}$ responders. This closely matched NAb valency for all subjects and groups from the original study [49].

\subsection{DENV-specific antibody depletions}

The DENV-specific antibodies were depleted from immune sera of all 10 subjects in order to estimate the relative contribution of serotype-specific and cross-reactive antibody to neutralization of DENV 1-4. To accomplish this, polystyrene beads were coated with purified DENV virions to selectively remove antibody to each serotype or a combination of serotypes and removal of antibody was confirmed by ELISA (Fig. 1). All single and combination serotype depletions reduced antibody binding against the respective DENV serotype(s) to background levels, while control depleted sera retained their binding capacity. Subject 2 had some DENVreactive antibody that was not completely depleted by this method. It is possible that this subject had a sub-population of high concentration but low avidity antibody that was inefficiently removed from serum by the virus-adsorbed beads. Importantly, the residual DENV-reactive antibody in this sample did not appear to contribute to neutralization.

\subsection{DENV type-specific and cross-reactive $N A b$}

The NAb titers were determined for DENV-specific antibody depleted and control depleted sera by FlowNT50 assay (Table 3). Homologous DENV antigen depletions reduced NAb titers to the respective DENV serotype to undetectable levels, except for sera

Table 1

Geometric mean neutralizing antibody titers and seroconversion for selected subjects compared to all DENV naïve subjects that received two doses of TDENV vaccine.

\begin{tabular}{|c|c|c|c|c|c|c|c|c|c|}
\hline \multirow[t]{2}{*}{ Group } & \multirow[t]{2}{*}{$\mathrm{N}=$} & \multicolumn{4}{|c|}{ NAb GMT ${ }^{\mathrm{a}, \mathrm{b}}$} & \multicolumn{4}{|c|}{ Seroconversion $^{\mathrm{C}}$} \\
\hline & & D1 & D2 & D3 & D4 & D1 & D2 & D3 & D4 \\
\hline PRE-F17 ${ }^{\mathrm{d}}$ & 14 & 198 & 666 & 75 & 279 & $93 \%$ & $100 \%$ & $71 \%$ & $79 \%$ \\
\hline TDEN F17 ${ }^{\mathrm{d}}$ & 15 & 50 & 156 & 31 & 70 & $73 \%$ & $80 \%$ & $67 \%$ & $73 \%$ \\
\hline TDEN F19 ${ }^{\mathrm{d}}$ & 12 & 118 & 226 & 52 & 46 & $83 \%$ & $100 \%$ & $83 \%$ & $67 \%$ \\
\hline Selected sera ${ }^{\mathrm{e}, \mathrm{f}, \mathrm{g}}$ & 10 & 144 & 2133 & 37 & 193 & $80 \%$ & $100 \%$ & $60 \%$ & $60 \%$ \\
\hline
\end{tabular}

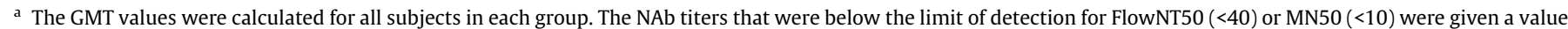
of 5 .

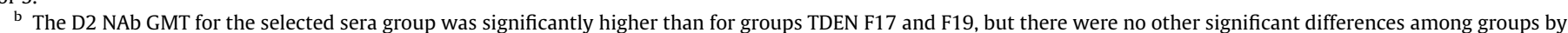
ANOVA with Tukey's multiple comparisons test $(\mathrm{p}<0.05)$.

c The levels of seroconversion for D1-D4 were not significantly different among groups by Fisher's exact test ( $\mathrm{p}<0.05)$.

d The data for PRE-F17, TDEN F17, and TDEN F19 were generated previously by MN50 assay [49].

e Sera used in current study to evaluate type-specific and cross-reactive NAb. Data were generated in this study by FlowNT50 assay.

f For the selected sera group, the D2 NAb GMT was significantly higher than the D3 NAb GMT, but there were no other significant differences for this group by ANOVA with Tukey's multiple comparisons test $(\mathrm{p}<0.05)$.

${ }^{g}$ For the selected sera group, the levels of seroconversion for D1-D4 were not significantly different by Fisher's exact test ( $\left.\mathrm{p}<0.05\right)$.

Table 2

Neutralizing antibody titers and valency of selected sera from DENV naïve subjects that received two doses of TDENV vaccine.

\begin{tabular}{|c|c|c|c|c|c|c|c|}
\hline \multirow[t]{2}{*}{ Subject number } & \multirow[t]{2}{*}{ Group } & \multirow[t]{2}{*}{ Study day ${ }^{\mathrm{a}}$} & \multicolumn{4}{|c|}{ NAb titer for: } & \multirow[t]{2}{*}{ NAb valency } \\
\hline & & & DENV-1 & DENV-2 & DENV-3 & DENV-4 & \\
\hline 17 & PRE-F17 & 210 & 863 & 3500 & 168 & 19,290 & Tetravalent \\
\hline 37 & PRE-F17 & 210 & 58 & 319 & $<40$ & 354 & Trivalent \\
\hline 91 & PRE-F17 & 210 & 2462 & 7231 & 209 & 4350 & Tetravalent \\
\hline 96 & PRE-F17 & 210 & 202 & 2489 & 60 & 6325 & Tetravalent \\
\hline 2 & TDEN F17 & 210 & $<40$ & 565 & $<40$ & $<40$ & Monovalent \\
\hline 14 & TDEN F17 & 210 & 185 & 1107 & 55 & 463 & Tetravalent \\
\hline 85 & TDEN F17 & 210 & 311 & 5297 & $<40$ & $<40$ & Bivalent \\
\hline 40 & TDEN F19 & 210 & $<40$ & 2991 & 170 & $<40$ & Bivalent \\
\hline 69 & TDEN F19 & 210 & 99 & 1050 & $<40$ & $<40$ & Bivalent \\
\hline 72 & TDEN F19 & 210 & 1056 & 9302 & 383 & 1327 & Tetravalent \\
\hline
\end{tabular}

\footnotetext{
a One month post-dose two of TDENV.
} 
a

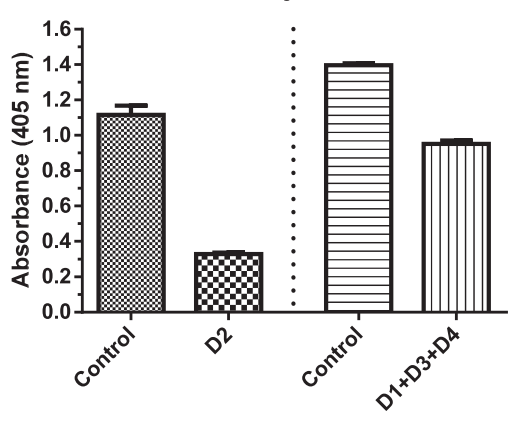

C

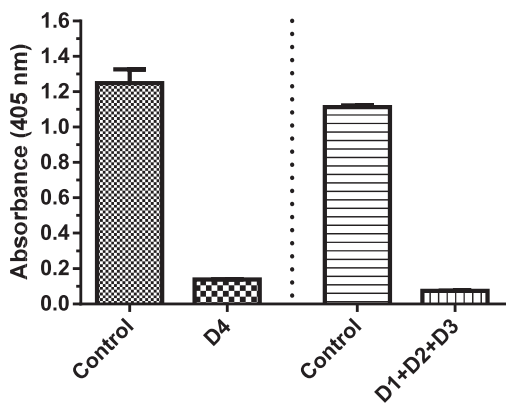

f

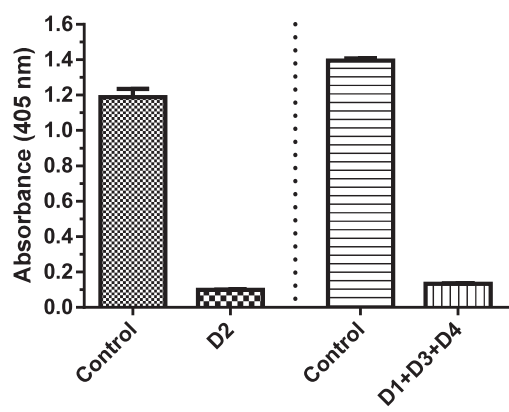

i

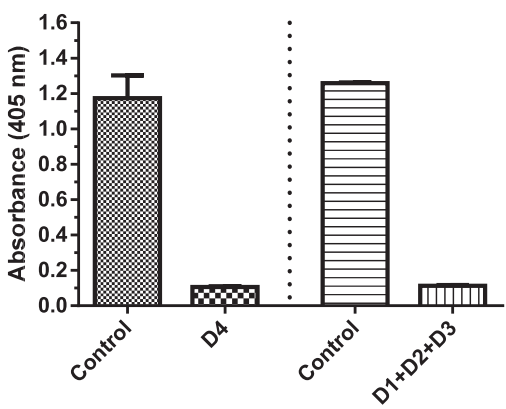

b

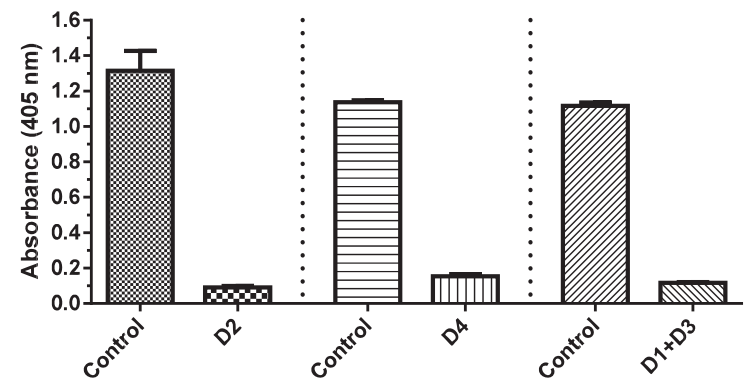

d

e

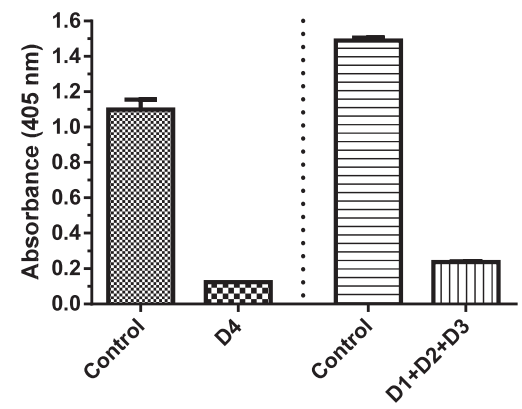

g

Subject 72

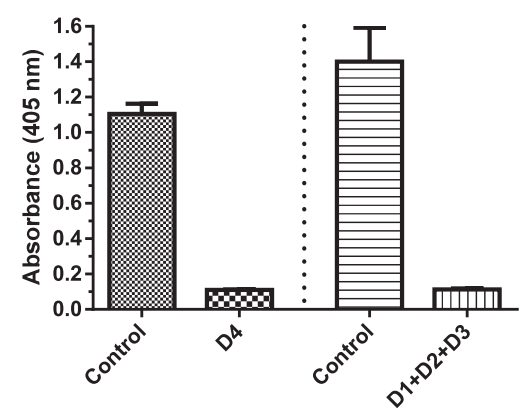

h

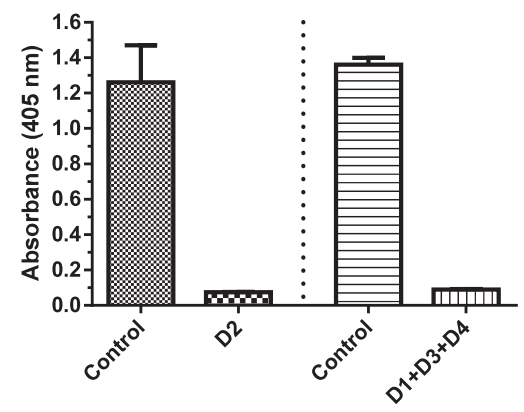

j
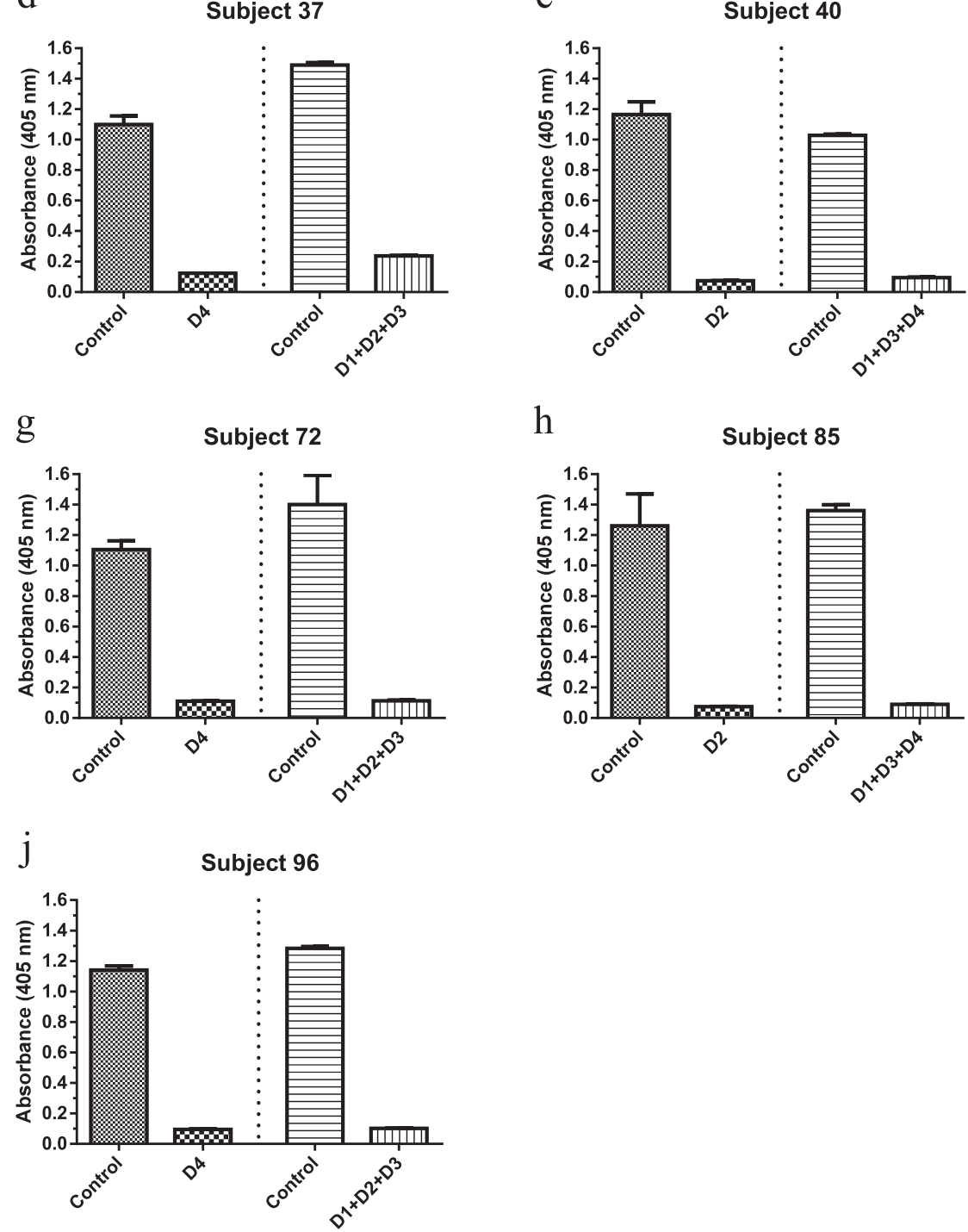

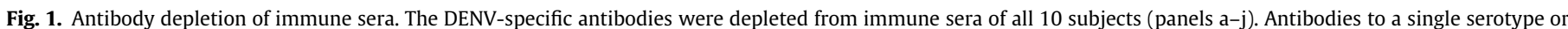

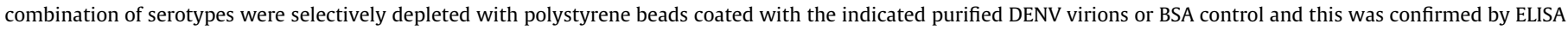

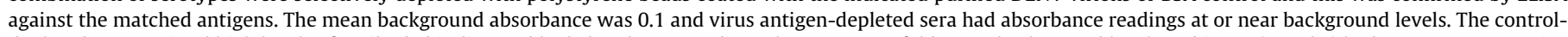

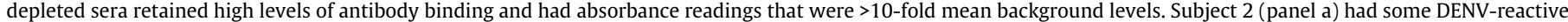

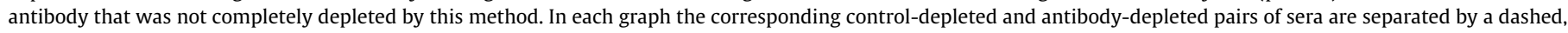
vertical line. The mean absorbance and SEM from replicate measurements are shown.

from subject 17, which had residual neutralizing activity against DENV-1. The relative levels of type-specific and cross-reactive $\mathrm{NAb}$ were interpreted based on the reduction in NAb titer following heterologous DENV antigen depletion and accounted for up to 3-fold assay-to-assay variability, which is common for neutralization assays. A reduction of $\leq 3$-fold was interpreted as predominantly type-specific $\mathrm{NAb},>3$-fold reduction interpreted as a mixture of type-specific and cross-reactive NAb, and a complete 
Table 3

Neutralizing antibody titers after depletion of immune serum with homologous and heterologous purified dengue virions.

\begin{tabular}{|c|c|c|c|c|c|}
\hline \multirow[t]{2}{*}{ Subject number } & \multirow[t]{2}{*}{ Depletion antigen(s) } & \multicolumn{4}{|c|}{ NAb titer for: } \\
\hline & & DENV-1 & DENV-2 & DENV-3 & DENV-4 \\
\hline \multirow[t]{3}{*}{2} & Control & $<40$ & 644 & 56 & $<40$ \\
\hline & D2 & $<40$ & $<40$ & $<40$ & $<40$ \\
\hline & $\mathrm{D} 1+\mathrm{D} 3+\mathrm{D} 4$ & $<40$ & 698 & $<40$ & $<40$ \\
\hline \multirow[t]{4}{*}{14} & Control & 104 & 782 & 64 & 568 \\
\hline & D2 & $<40$ & $<40$ & $<40$ & 374 \\
\hline & D4 & $<40$ & 242 & $<40$ & $<40$ \\
\hline & D1 + D3 & $<40$ & 233 & $<40$ & 224 \\
\hline \multirow[t]{3}{*}{17} & Control & 1072 & 680 & 314 & $>3240$ \\
\hline & D4 & 638 & 107 & $<40$ & $<40$ \\
\hline & $\mathrm{D} 1+\mathrm{D} 2+\mathrm{D} 3$ & 294 & $<40$ & $<40$ & $>3240$ \\
\hline \multirow[t]{3}{*}{37} & Control & $<40$ & 170 & $<40$ & 364 \\
\hline & D4 & $<40$ & 75 & $<40$ & $<40$ \\
\hline & $\mathrm{D} 1+\mathrm{D} 2+\mathrm{D} 3$ & $<40$ & $<40$ & $<40$ & 258 \\
\hline \multirow[t]{3}{*}{40} & Control & $<40$ & 740 & 245 & $<40$ \\
\hline & D2 & $<40$ & $<40$ & 159 & $<40$ \\
\hline & $\mathrm{D} 1+\mathrm{D} 3+\mathrm{D} 4$ & $<40$ & 763 & $<40$ & $<40$ \\
\hline \multirow[t]{3}{*}{69} & Control & $<40$ & 63 & $<40$ & $<40$ \\
\hline & D2 & $<40$ & $<40$ & $<40$ & $<40$ \\
\hline & $\mathrm{D} 1+\mathrm{D} 3+\mathrm{D} 4$ & $<40$ & $<40$ & $<40$ & $<40$ \\
\hline \multirow[t]{3}{*}{72} & Control & 187 & 310 & 234 & 575 \\
\hline & D4 & $<40$ & $<40$ & $<40$ & $<40$ \\
\hline & $\mathrm{D} 1+\mathrm{D} 2+\mathrm{D} 3$ & $<40$ & $<40$ & $<40$ & 77 \\
\hline \multirow[t]{3}{*}{85} & Control & 158 & 219 & $<40$ & $<40$ \\
\hline & D2 & $<40$ & $<40$ & $<40$ & $<40$ \\
\hline & $\mathrm{D} 1+\mathrm{D} 3+\mathrm{D} 4$ & $<40$ & $<40$ & $<40$ & $<40$ \\
\hline \multirow[t]{3}{*}{91} & Control & 133 & 855 & 331 & 4596 \\
\hline & D4 & $<40$ & 176 & $<40$ & $<40$ \\
\hline & $\mathrm{D} 1+\mathrm{D} 2+\mathrm{D} 3$ & $<40$ & $<40$ & $<40$ & 6931 \\
\hline \multirow[t]{3}{*}{96} & Control & 104 & 407 & 204 & 1203 \\
\hline & D4 & $<40$ & 133 & $<40$ & $<40$ \\
\hline & $\mathrm{D} 1+\mathrm{D} 2+\mathrm{D} 3$ & $<40$ & $<40$ & $<40$ & 3185 \\
\hline
\end{tabular}

Table 4

Characteristics of neutralizing antibody responses to DENV 1-4 and serotype-specific valency.

\begin{tabular}{|c|c|c|c|c|c|}
\hline \multirow[t]{2}{*}{ Subject number } & \multicolumn{4}{|c|}{ NAb responses for ${ }^{a}$} & \multirow[t]{2}{*}{ Type-specific NAb valency } \\
\hline & DENV-1 & DENV-2 & DENV-3 & DENV-4 & \\
\hline 2 & none $^{\mathrm{b}}$ & type $^{c}$ & $\operatorname{cross}^{\mathrm{d}}$ & none & Mono \\
\hline 14 & cross & $\operatorname{mix}^{\mathrm{e}}$ & cross & type & $\mathrm{Bi}$ \\
\hline 17 & type & $\operatorname{mix}$ & cross & type & Tri \\
\hline 37 & none & type & none & type & $\mathrm{Bi}$ \\
\hline 40 & none & type & type & none & $\mathrm{Bi}$ \\
\hline 69 & none & cross & none & none & None \\
\hline 72 & cross & cross & cross & $\operatorname{mix}$ & Mono \\
\hline 85 & cross & cross & none & none & None \\
\hline 91 & cross & $\operatorname{mix}$ & cross & type & $\mathrm{Bi}$ \\
\hline 96 & cross & $\operatorname{mix}$ & cross & type & $\mathrm{Bi}$ \\
\hline
\end{tabular}

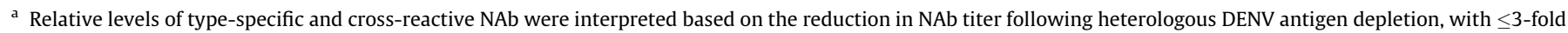

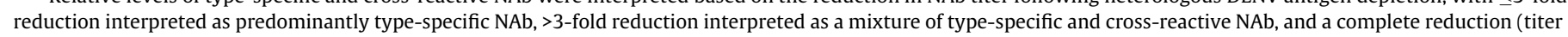
$<40$ ) interpreted as predominantly cross-reactive NAb.

b None = undetectable $\mathrm{NAb}$ titer to that serotype in the depletion experiment.

c Type $=$ DENV serotype-specific NAb.

${ }^{\mathrm{d}}$ Cross $=$ DENV cross-reactive NAb.

e $\mathrm{Mix}=$ Mixture of DENV serotype-specific and cross-reactive NAb.

reduction (titer $<40$ ) interpreted as predominantly cross-reactive NAb. Subject 91, for example, neutralized DENV 1-4 with titers of $133,855,331$, and 4596 , respectively. Depletion of this subject's serum with DENV-4 antigen reduced the NAb titer to DENV-1 and DENV-3 to undetectable levels and indicated that these NAb responses were primarily cross-reactive. The NAb titer to DENV-2 remained detectable after DENV-4 antigen depletion, but was reduced by 4.9 -fold, indicating a mixture of type-specific and cross-reactive DENV-2 NAb. Depletion of this subject's serum with a combination of DENV-1, 2, and 3 had no apparent effect on the $\mathrm{NAb}$ titer to DENV-4 ( $\leq 3$-fold reduction) and indicated that the DENV-4 NAb is primarily type-specific. The NAb titer data for depleted sera from all 10 subjects were interpreted using these criteria.

The NAb response characteristics for DENV 1-4 and the typespecific NAb valency for each subject are indicated in Table 4. Subjects with a mixture of type-specific and cross-reactive NAb were included for type-specific NAb valency. Two subjects (69 and 85) 

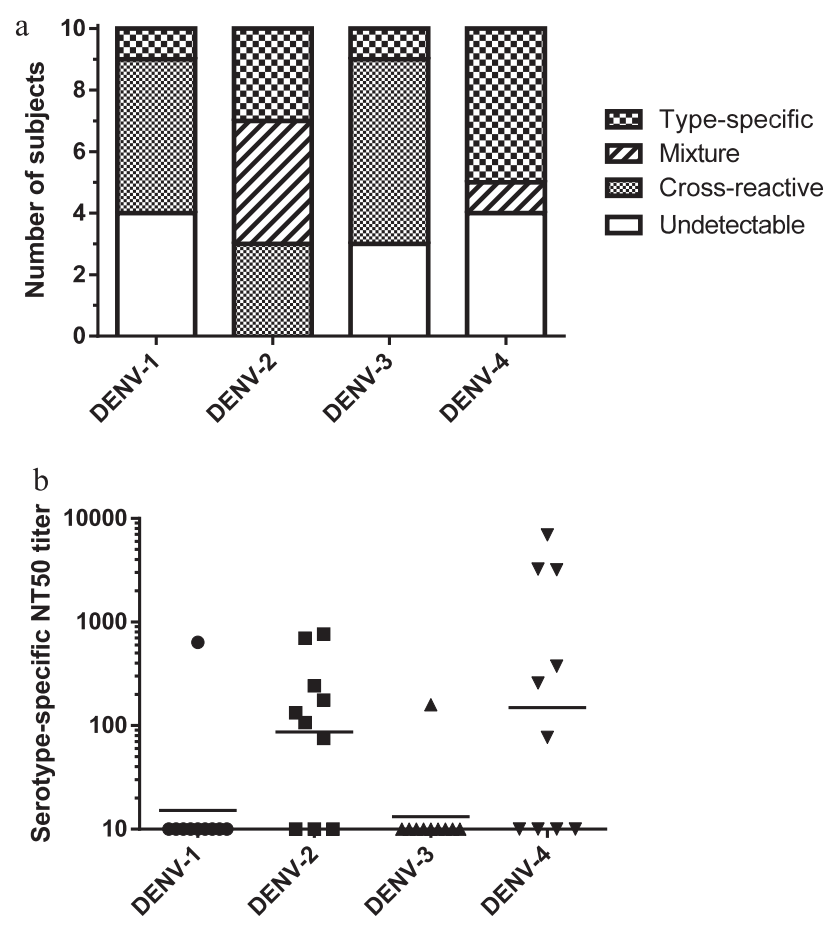

Fig. 2. Serotype specificity of neutralizing antibody responses. In panel a, the number of subjects with type-specific, mixture of type-specific and cross-reactive, cross-reactive only, or undetectable neutralizing antibody to DENV 1-4 are indicated. In panel b, the DENV 1-4 serotype-specific 50\% neutralization (NT50) titers are shown. These are the NT50 titers reported after heterologous antibody depletion in Table 3. Sera with undetectable serotype-specific neutralizing antibody $(<40)$ were given an NT50 value of 10 . The geometric mean neutralizing antibody titers are indicated by a bar.

had undetectable levels of type-specific NAb to any serotype but both had cross-reactive NAb to DENV-2. Subjects 2 and 72 had monovalent type-specific NAb responses to DENV-2 and DENV-4, respectively, and cross-reactive NAb to some or all of the other serotypes. One subject, 17, had a trivalent type-specific NAb response to DENV-1, -2 and -4 , and a cross-reactive NAb response to DENV3. Half of the subjects that we tested had a bivalent type-specific $\mathrm{NAb}$ response. One subject, 40 , had type-specific NAb to DENV-2 and DENV-3. The other four subjects $(14,37,91$ and 96) had type-specific NAb to DENV-2 and DENV-4 and undetectable or cross-reactive NAb to the other serotypes.

The characteristics of NAb responses to DENV 1-4 are summarized in Fig. 2a and the serotype-specific NAb titers and GMTs are shown in Fig. 2b. The majority of subjects had type-specific NAb responses to DENV-2 and DENV-4 and cross-reactive NAb responses to DENV-1 and DENV-3. The DENV 1-4 type-specific NAb GMTs for these subjects were $<40,87,<40$, and 149, respectively.

\subsection{Vaccine virus RNAemia}

All subjects were tested for DENV 1-4 vaccine virus RNAemia by RT-qPCR on two separate study visits in a 14 day window after both doses of vaccine. Two of 10 subjects with sera that were selected for the current study had detectable levels of vaccine virus RNAemia. Subject 17 had $4.6 \log 10 \mathrm{GEQ} / \mathrm{ml}$ of DENV-4 at 14 days post-dose 2 of vaccine. Subject 96 had $5.2 \log 10 \mathrm{GEQ} / \mathrm{ml}$ of DENV-4 at 8 days post-dose 2 of vaccine. The sera from these two subjects also had high titer DENV-4 type-specific NAb of $>3240$ and 3185 , respectively. Approximately 214 subjects in four separate clinical studies have been vaccinated with TDENV [47-50] and detectable RNAemia has been reported for DENV-2 (5 subjects), DENV-3 (1 subject), and DENV-4 (15 subjects). There were almost certainly more subjects with vaccine virus RNAemia that was not captured by the 1 or 2 days of sampling done in these studies. Based on these limited data, replication of the vaccine viruses in humans appears to follow the pattern DENV-4 > DENV$2>$ DENV-3 $>$ DENV-1. This is similar to the observed pattern of type-specific NAb responses of the 10 subjects in this study, which were predominantly elicited by DENV-2 and DENV-4.

\section{Discussion}

Primary DENV infections elicit both type-specific and crossreactive NAbs that correlate with protection against that serotype, but not durable cross-protection against other serotypes [2,12,22]. Post-primary DENV infections elicit more broadly cross-reactive NAbs and correlate with a longer period of cross-protection [47]. The DENV vaccines in clinical development, including the WRAIR TDENV vaccine consists of all four serotypes delivered simultaneously and it was unclear what effect that would have on NAb responses. Therefore, we evaluated levels of type-specific and cross-reactive NAb in sera from flavivirus naive subjects that received two doses of the WRAIR TDENV vaccine.

Sera from subjects in a previous phase II clinical study were selected for testing based on high levels of neutralizing antibody to DENV 1-4 and consent for future testing. For the subset of study sera that we selected, seroconversion levels were not significantly different between DENV serotypes. Also, the only significant difference in NAb GMTs were between DENV-2 and DENV-3. In general, seroconversion and GMT were not good predictors of type-specific NAb responses. A much higher proportion of sera from the 10 subjects that we evaluated had DENV-2 and DENV-4 type-specific NAb than DENV-1 or DENV-3 type-specific NAb. Most subjects had cross-reactive NAb to DENV-1 and DENV-3, which may have actually been elicited by the better replicating DENV-2 and DENV-4 vaccine viruses. Thus, many of these subjects might not have specifically responded to DENV-1 or DENV-3 vaccine viruses, even though they were given a DENV 1-4 tetravalent mixture.

The DENV-2 and DENV-4 components of the WRAIR TDENV vaccine were most frequently detected replicating in vaccinated subjects in four separate clinical studies [47-50]. This observation correlates with the relatively high proportion of DENV-2 and DENV-4 type-specific NAb responses observed in the current study. Some subjects did have type-specific NAb to DENV-1 and DENV-3 after vaccination, indicating that these vaccine viruses probably replicated in some individuals. Unfortunately, only 1 or 2 samples were collected post-vaccination for evaluating RNAemia, which means that many RNAemia positive time-points were likely missed. Therefore, we could not determine if detectable levels of vaccine virus replication were required to elicit type-specific immunity. However, the two subjects with detectable levels of DENV-4 RNAemia in the current study also produced high titer DENV-4 type-specific NAb.

Natural human DENV infections elicit potently neutralizing serotype-specific antibody, which is a better long-term correlate of protection than cross-reactive NAb [12,55]. DENV vaccine development has been complicated by the need to simultaneously vaccinate with all four serotypes, which differs from natural infections that are acquired sequentially. The DENV 1-4 components of live attenuated vaccines that are currently licensed or in clinical development each have some level of unbalanced replicative fitness in humans $[31,33,56]$. It is conceivable that tetravalent, type-specific immunity elicited by balanced replication of all four vaccine viruses is not required for protection, but a lack of typespecific immunity to one or more serotypes could result in poor 
overall clinical efficacy. Evidence supporting this comes from phase III studies of the CYD-TDV vaccine [8-10]. Naïve subjects that received this vaccine had similar DENV 1-4 NAb titers but primarily had type-specific NAb to DENV-4, which was attributed to better replication of the DENV-4 vaccine virus [19,56], and resulted in better levels of protection compared to DENV-1 and DENV-2. This, in part, illustrates the importance of evaluating serotypespecific NAb responses elicited by tetravalent DENV vaccines.

\section{Acknowledgements}

This work was funded by the Military Infectious Disease Research Program.

\section{Conflict of interest}

\section{The authors report no conflict of interest.}

\section{References}

[1] Bhatt S, Gething PW, Brady OJ, Messina JP, Farlow AW, Moyes CL, et al. The global distribution and burden of dengue. Nature 2013;496:504-7.

[2] Sabin AB. Research on dengue during World War II. Am J Tropical Med Hygiene $1952 ; 1: 30-50$

[3] Waggoner JJ, Balmaseda A, Gresh L, Sahoo MK, Montoya M, Wang C, et al. Homotypic dengue virus reinfections in nicaraguan children. J Infect Dis 2016;214:986-93.

[4] Anderson KB, Gibbons RV, Cummings DA, Nisalak A, Green S, Libraty DH, et al A shorter time interval between first and second dengue infections is associated with protection from clinical illness in a school-based cohort in Thailand. J Infect Dis 2014;209:360-8.

[5] Rothman AL. Cellular immunology of sequential dengue virus infection and its role in disease pathogenesis. Curr Topics Microbiol Immunol 2010:338:83-98.

[6] Flipse J, Smit JM. The complexity of a dengue vaccine: a review of the human antibody response. PLoS Neglected Tropical Dis 2015;9:e0003749.

[7] Patel B, Longo P, Miley MJ, Montoya M, Harris E, de Silva AM. Dissecting the human serum antibody response to secondary dengue virus infections. PLoS Neglected Tropical Dis 2017;11:e0005554.

[8] Sabchareon A, Wallace D, Sirivichayakul C, Limkittikul K, Chanthavanich P, Suvannadabba S, et al. Protective efficacy of the recombinant, live-attenuated, CYD tetravalent dengue vaccine in Thai schoolchildren: a randomised, controlled phase 2b trial. Lancet 2012;380:1559-67.

[9] Villar L, Dayan GH, Arredondo-Garcia JL, Rivera DM, Cunha R, Deseda C, et al. Efficacy of a tetravalent dengue vaccine in children in Latin America. New Engl J Med 2015;372:113-23.

[10] Capeding MR, Tran NH, Hadinegoro SR, Ismail HI, Chotpitayasunondh T, Chua MN, et al. Clinical efficacy and safety of a novel tetravalent dengue vaccine in healthy children in Asia: a phase 3, randomised, observer-masked, placebocontrolled trial. Lancet 2014;384:1358-65.

[11] Roehrig JT. Antigenic structure of flavivirus proteins. Adv in virus Res 2003;59:141-75.

[12] de Alwis R, Smith SA, Olivarez NP, Messer WB, Huynh JP, Wahala WM, et al Identification of human neutralizing antibodies that bind to complex epitopes on dengue virions. Proc Natl Acad Sci USA 2012;109:7439-44.

[13] Fibriansah G, Ibarra KD, Ng TS, Smith SA, Tan JL, Lim XN, et al. DENGUE VIRUS. Cryo-EM structure of an antibody that neutralizes dengue virus type 2 by locking E protein dimers. Science 2015;349:88-91.

[14] Fibriansah G, Tan JL, Smith SA, de Alwis R, Ng TS, Kostyuchenko VA, et al. A highly potent human antibody neutralizes dengue virus serotype 3 by binding across three surface proteins. Nat Commun 2015;6:6341.

[15] Fibriansah G, Tan JL, Smith SA, de Alwis AR, Ng TS, Kostyuchenko VA, et al. A potent anti-dengue human antibody preferentially recognizes the conformation of E protein monomers assembled on the virus surface. EMBO Mol Med 2014;6:358-71.

[16] Dejnirattisai W, Wongwiwat W, Supasa S, Zhang X, Dai X, Rouvinski A, et al. A new class of highly potent, broadly neutralizing antibodies isolated from viremic patients infected with dengue virus. Nat Immunol 2015;16:170-7.

[17] Rouvinski A, Guardado-Calvo P, Barba-Spaeth G, Duquerroy S, Vaney MC, Kikuti CM, et al. Recognition determinants of broadly neutralizing human antibodies against dengue viruses. Nature 2015;520:109-13.

[18] Teoh EP, Kukkaro P, Teo EW, Lim AP, Tan TT, Yip A, et al. The structural basis for serotype-specific neutralization of dengue virus by a human antibody. Sci Transl Med 2012;4:139ra83.

[19] Henein S, Swanstrom J, Byers AM, Moser JM, Shaik SF, Bonaparte M, et al. Dissecting antibodies induced by a chimeric yellow fever-dengue, liveattenuated, tetravalent dengue vaccine (CYD-TDV) in naive and dengue exposed individuals. J Infect Dis 2016.
[20] Olkowski S, Forshey BM, Morrison AC, Rocha C, Vilcarromero S, Halsey ES, et al. Reduced risk of disease during postsecondary dengue virus infections. J Infect Dis 2013;208:1026-33.

[21] Tsai WY, Durbin A, Tsai JJ, Hsieh SC, Whitehead S, Wang WK. Complexity of neutralizing antibodies against multiple dengue virus serotypes after heterotypic immunization and secondary infection revealed by in-depth analysis of cross-reactive antibodies. J Virol 2015;89:7348-62.

[22] de Alwis R, Williams KL, Schmid MA, Lai CY, Patel B, Smith SA, et al. Dengue viruses are enhanced by distinct populations of serotype cross-reactive antibodies in human immune sera. PLoS Pathogens 2014;10:e1004386.

[23] Vannice KS, Durbin A, Hombach J. Status of vaccine research and development of vaccines for dengue. Vaccine 2016:34:2934-8.

[24] Gailhardou S, Skipetrova A, Dayan GH, Jezorwski J, Saville M, Van der Vliet D, et al. Safety overview of a recombinant live-attenuated tetravalent dengue vaccine: pooled analysis of data from 18 clinical trials. PLoS Neglected Tropical Dis 2016;10:e0004821.

[25] Lopez P, Lanata CF, Zambrano B, Cortes M, Andrade T, Amemiya I, et al. Immunogenicity and safety of yellow fever vaccine (stamaril) when administered concomitantly with a tetravalent dengue vaccine candidate in healthy toddlers at 12-13 months of age in Colombia and Peru: a randomized trial. Pediat Infect Dis J 2016;35:1140-7.

[26] Olivera-Botello G, Coudeville L, Fanouillere K, Guy B, Chambonneau L, Noriega $\mathrm{F}$, et al. Tetravalent dengue vaccine reduces symptomatic and asymptomatic dengue virus infections in healthy children and adolescents aged 2-16 years in Asia and Latin America. J Infect Dis 2016;214:994-1000.

[27] Whitehead SS. Development of TV003/TV005, a single dose, highly immunogenic live attenuated dengue vaccine; what makes this vaccine different from the Sanofi-Pasteur CYD vaccine? Exp Rev Vaccines 2016;15:509-17.

[28] Durbin AP, Kirkpatrick BD, Pierce KK, Carmolli MP, Tibery CM, Grier PL, et al. A 12-month-interval dosing study in adults indicates that a single dose of the national institute of allergy and infectious diseases tetravalent dengue vaccine induces a robust neutralizing antibody response. J Infect Dis 2016;214:832-5.

[29] Kirkpatrick BD, Whitehead SS, Pierce KK, Tibery CM, Grier PL, Hynes NA, et al. The live attenuated dengue vaccine TV003 elicits complete protection against dengue in a human challenge model. Sci Transl Med 2016;8:330ra36.

[30] Kirkpatrick BD, Durbin AP, Pierce KK, Carmolli MP, Tibery CM, Grier PL, et al. Robust and balanced immune responses to all 4 dengue virus serotypes following administration of a single dose of a live attenuated tetravalent dengue vaccine to healthy, flavivirus-naive adults. J Infect Dis 2015;212:702-10.

[31] Durbin AP, Kirkpatrick BD, Pierce KK, Elwood D, Larsson CJ, Lindow JC, et al. A single dose of any of four different live attenuated tetravalent dengue vaccines is safe and immunogenic in flavivirus-naive adults: a randomized, doubleblind clinical trial. J Infect Dis 2013;207:957-65.

[32] Sirivichayakul C, Barranco-Santana EA, Esquilin-Rivera I, Oh HM, Raanan M, Sariol CA, et al. Safety and immunogenicity of a tetravalent dengue vaccine candidate in healthy children and adults in dengue-endemic regions: a randomized, placebo-controlled phase 2 study. J Infect Dis 2016;213:1562-72.

[33] George SL, Wong MA, Dube TJ, Boroughs KL, Stovall JL, Luy BE, et al. Safety and immunogenicity of a live attenuated tetravalent dengue vaccine candidate in flavivirus-naive adults: a randomized, double-blinded phase 1 clinical trial. J Infect Dis 2015;212:1032-41.

[34] Osorio JE, Partidos CD, Wallace D, Stinchcomb DT. Development of a recombinant, chimeric tetravalent dengue vaccine candidate. Vaccine 2015;33:7112-20.

[35] Rupp R, Luckasen GJ, Kirstein JL, Osorio JE, Santangelo JD, Raanan M, et al. Safety and immunogenicity of different doses and schedules of a live attenuated tetravalent dengue vaccine (TDV) in healthy adults: a phase $1 \mathrm{~b}$ randomized study. Vaccine 2015;33:6351-9.

[36] Thomas SJ, Rothman AL. Trials and tribulations on the path to developing a dengue vaccine. Vaccine 2015;33(Suppl 4):D24-31.

[37] Innis BL, Eckels KH. Progress in development of a live-attenuated, tetravalent dengue virus vaccine by the United States Army Medical Research and Materiel Command. Am J Tropical Med Hygiene 2003;69:1-4.

[38] Edelman R, Wasserman SS, Bodison SA, Putnak RJ, Eckels KH, Tang D, et al. Phase I trial of 16 formulations of a tetravalent live-attenuated dengue vaccine. Am J Tropical Med Hygiene 2003;69:48-60.

[39] Innis BL, Eckels KH, Kraiselburd E, Dubois DR, Meadors GF, Gubler DJ, et al. Virulence of a live dengue virus vaccine candidate: a possible new marker of dengue virus attenuation. J Infect Dis 1988;158:876-80.

[40] Edelman R, Tacket CO, Wasserman SS, Vaughn DW, Eckels KH, Dubois DR, et al. A live attenuated dengue- 1 vaccine candidate (45AZ5) passaged in primary dog kidney cell culture is attenuated and immunogenic for humans. J Infect Dis 1994:170:1448-55.

[41] McKee Jr KT, Bancroft WH, Eckels KH, Redfield RR, Summers PL, Russell PK. Lack of attenuation of a candidate dengue 1 vaccine (45AZ5) in human volunteers. Am J Tropical Med Hygiene 1987;36:435-42.

[42] Hoke Jr CH, Malinoski FJ, Eckels KH, Scott RM, Dubois DR, Summers PL, et al. Preparation of an attenuated dengue 4 (341750 Carib) virus vaccine. II. Safety and immunogenicity in humans. Am J Tropical Med Hygiene 1990;43:219-26.

[43] Marchette NJ, Dubois DR, Larsen LK, Summers PL, Kraiselburd EG, Gubler DJ, et al. Preparation of an attenuated dengue 4 (341750 Carib) virus vaccine. I. Pre-clinical studies. Am J Tropical Med Hygiene 1990;43:212-8.

[44] Kanesa-Thasan N, Edelman R, Tacket CO, Wasserman SS, Vaughn DW, Coster TS, et al. Phase 1 studies of Walter Reed Army Institute of Research candidate 
attenuated dengue vaccines: selection of safe and immunogenic monovalent vaccines. Am J Tropical Med Hygiene 2003;69:17-23.

[45] Sun W, Edelman R, Kanesa-Thasan N, Eckels KH, Putnak JR, King AD, et al. Vaccination of human volunteers with monovalent and tetravalent liveattenuated dengue vaccine candidates. Am J Tropical Med Hygiene 2003;69:24-31.

[46] Sun W, Cunningham D, Wasserman SS, Perry J, Putnak JR, Eckels KH, et al. Phase 2 clinical trial of three formulations of tetravalent live-attenuated dengue vaccine in flavivirus-naive adults. Human Vaccines 2009;5:33-40.

[47] Watanaveeradej V, Simasathien S, Nisalak A, Endy TP, Jarman RG, Innis BL, et al. Safety and immunogenicity of a tetravalent live-attenuated dengue vaccine in flavivirus-naive infants. Am J Tropical Med Hygiene 2011;85:341-51.

[48] Simasathien S, Thomas SJ, Watanaveeradej V, Nisalak A, Barberousse C, Innis $\mathrm{BL}$, et al. Safety and immunogenicity of a tetravalent live-attenuated dengue vaccine in flavivirus naive children. Am J Tropical Med Hygiene 2008;78:426-33.

[49] Thomas SJ, Eckels KH, Carletti I, De La Barrera R, Dessy F, Fernandez S, et al. A phase II, randomized, safety and immunogenicity study of a re-derived, liveattenuated dengue virus vaccine in healthy adults. Am J Tropical Med Hygiene 2013;88:73-88.

[50] Watanaveeradej V, Gibbons RV, Simasathien S, Nisalak A, Jarman RG, Kerdpanich A, et al. Safety and immunogenicity of a rederived, live- attenuated dengue virus vaccine in healthy adults living in Thailand: randomized trial. Am J Tropical Med Hygiene 2014;91:119-28.

[51] Schmidt AC, Lin L, Martinez LJ, Ruck RC, Eckels KH, Collard A, et al. Phase 1 randomized study of a tetravalent dengue purified inactivated vaccine in healthy adults in the United States. Am J Tropical Med Hygiene 2017;96:1325-37.

[52] Wahala WM, Kraus AA, Haymore LB, Accavitti-Loper MA, de Silva AM. Dengue virus neutralization by human immune sera: role of envelope protein domain III-reactive antibody. Virology 2009;392:103-13.

[53] Putnak R, Barvir DA, Burrous JM, Dubois DR, D’Andrea VM, Hoke CH, et al Development of a purified, inactivated, dengue-2 virus vaccine prototype in Vero cells: immunogenicity and protection in mice and rhesus monkeys. J Infect Dis 1996;174:1176-84.

[54] Kraus AA, Messer W, Haymore LB, de Silva AM. Comparison of plaque- and flow cytometry-based methods for measuring dengue virus neutralization. J Clin Microbiol 2007:45:3777-80.

[55] Endy TP. Human immune responses to dengue virus infection: lessons learned from prospective cohort studies. Front Immunol 2014;5:183.

[56] Guy B, Briand O, Lang J, Saville M, Jackson N. Development of the Sanof Pasteur tetravalent dengue vaccine: one more step forward. Vaccine 2015;33:7100-11 